\title{
DNA-Binding and Topoisomerase-I-Suppressing Activities of Novel Vanadium Compound Van-7
}

\author{
Xiao-mei Mo, ${ }^{1,2}$ Zhan-fang Chen, ${ }^{2}$ Xin Qi, ${ }^{1}$ Yan-tuan Li, ${ }^{1}$ and Jing Li ${ }^{1}$ \\ ${ }^{1}$ Key Laboratory of Marine Drugs, Ministry of Education, School of Medicine and Pharmacy, Ocean University of China, \\ 5 Yu-Shan Road, Qingdao 266003, China \\ ${ }^{2}$ The Department of Pharmacy, Qingdao Women and Children Hospital, 127 Liao-Yang West Road, Qingdao 266034, China
}

Correspondence should be addressed to Jing Li, lijing_ouc@163.com

Received 17 July 2012; Revised 17 August 2012; Accepted 17 August 2012

Academic Editor: Zhe-Sheng Chen

Copyright (c) 2012 Xiao-mei Mo et al. This is an open access article distributed under the Creative Commons Attribution License, which permits unrestricted use, distribution, and reproduction in any medium, provided the original work is properly cited.

\begin{abstract}
Vanadium compounds were studied during recent years to be considered as a representative of a new class of nonplatinum metal anticancer agents in combination to its low toxicity. Here, we found a vanadium compound Van-7 as an inhibitor of Topo I other than Topo II using topoisomerase-mediated supercoiled DNA relaxation assay. Agarose gel electrophoresis and comet assay showed that Van-7 treatment did not produce cleavable complexes like HCPT, thereby suggesting that Topo I inhibition occurred upstream of the relegation step. Further studies revealed that Van-7 inhibited Topo I DNA binding involved in its intercalating DNA. Van-7 did not affect the catalytic activity of DNase I even up to $100 \mu \mathrm{M}$. Van-7 significantly suppressed the growth of cancer cell lines with $\mathrm{IC}_{50}$ at nanomolar concentrations and arrested cell cycle of A549 cells at G2/M phase. All these results indicate that Van-7 is a potential selective Topo I inhibitor with anticancer activities as a kind of Topo I suppressor, not Topo I poison.
\end{abstract}

\section{Introduction}

DNA topoisomerases which catalyze the interconversions of various topological states of DNA were originally discovered as activities that change the superhelical structure of closed circular DNAs [1]. Based on their functional mechanisms, DNA topoisomerases have been classified into two types: type I DNA topoisomerases (Topo I) break and rejoin only one of the two strands during catalysis, while type II DNA topoisomerases (Topo II) break and rejoin both strands for each DNA strand-passing reaction. Studies have shown that Topo I is associated with actively transcribed genes, whereas Topo II is required for DNA replication and for successful traverse of mitosis $[2,3]$. Thus DNA topoisomerases modify the topological states of DNA which facilitate various DNA transactions such as DNA replication, recombination, chromosome condensation/decondensation, and chromosome segregation. Previous studies have suggested that Topo I does not require a nucleotide cofactor or any other energy source to relax supercoiled DNA while Topo II cannot relax supercoiled DNA without ATP [4].
Studies have identified DNA topoisomerases as therapeutic targets in cancer chemotherapy [5]. Topo I is a molecular target of hydroxycamptothecine (HCPT) while Topo II is a molecular target of a number of clinically useful anticancer drugs such as etoposide (VP-16), doxorubicin, mitoxantrone and (N-[4-(9-acridinylamino)-3-methoxyphenyl] methanesulphonanilide) (m-AMSA). Other compounds such as saintopin, intoplicine, indoloquinolinedione derivatives, $\beta$ lapachone, and related naphthoquinones have been shown to act on both Topo I and Topo II [6-9].

The success of platinum as anticancer agent has stimulated a search for other metallic cytotoxic compounds with equal or greater anticancer activity and lower toxicity [10]. Three platinum-based antineoplastic agents are now in routine clinical practice: cisplatin, carboplatin, and oxaliplatin [11]. Although these heavy metal agents are active against a variety of cancers, their clinical applications are associated with severe side effects including gastrointestinal symptoms (nausea, vomiting, diarrhea, and abdominal pain), renal tubular injury, neuron-muscular complications, and ototoxicity. In addition, the use of platinum is limited in many 


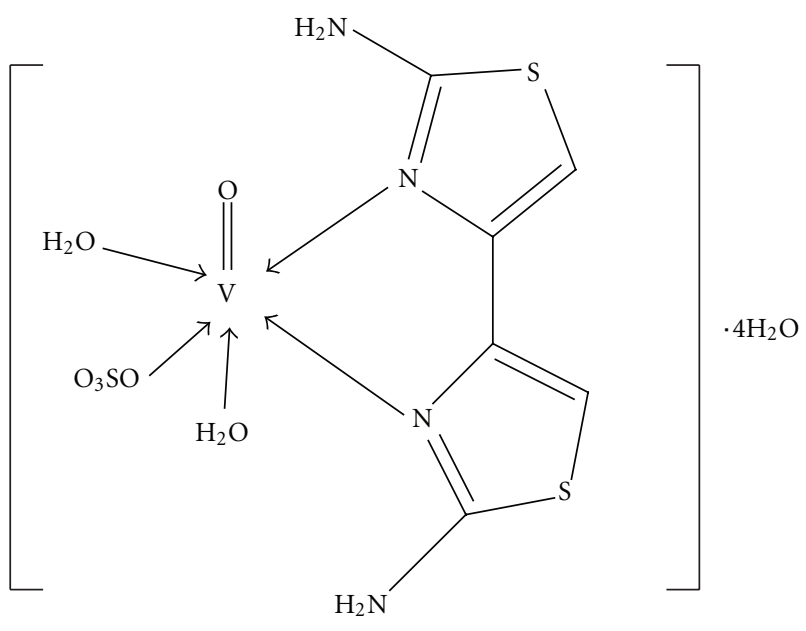

Figure 1: Van-7, $\left[\mathrm{VO}\left(\mathrm{SO}_{4}\right)\left(\mathrm{C}_{6} \mathrm{H}_{6} \mathrm{~N}_{4} \mathrm{~S}_{2}\right)\left(\mathrm{H}_{2} \mathrm{O}\right)_{2}\right] 4 \mathrm{H}_{2} \mathrm{O}$.

tumor types by primary and acquired resistance to this agent [12]. This has led to an ongoing quest for the discovery of nonplatinum metals that may extend the spectrum of activity of metal-based drugs [13]. Vanadium compounds have been widely reported to exert preventive effects against chemical carcinogenesis on animals, by modifying various xenobiotic enzymes and inhibiting carcinogen-derived active metabolites $[14,15]$. In the present paper, we investigated the effects of a new vanadium compound, diaqua (2,2' -diamino4,4' -bi-1,3-thiazole) oxosulfato-vanadium (IV) tetrahydrate (Van-7, Figure 1) [16], on the capability of inhibiting Topo I and anticancer activities in vitro. We find that the Van-7 is a potential Topo I inhibitor as a kind of Topo I suppressor other than Topo I poison.

\section{Materials and Methods}

2.1. Drugs and Reagents. Van-7 in light blue color crystalloid was provided by the Pharmacochemistry Department III of Marine and Food institute, Ocean University of China and diluted in double-distilled water. The purity was determined by RP-HPLC to be more than $99.0 \%$. Anal. Calcd for $\mathrm{VC}_{6} \mathrm{H}_{18} \mathrm{~N}_{4} \mathrm{O}_{11} \mathrm{~S}_{3}$ (M.W. 469.36): C, 15.35; H, 3.86; N, 11.94\%. Found: C, 15.30; H, 3.81; N, 11.92\%. Supercoiled plasmid pBR322 was purchased from Takara Biotechnology Company (Dalian, China). 3-[4,5-dimethylthiazol-2-yl]-2,5diphenyltetrazolium bromide (MTT), Proteinase $\mathrm{K}$, and SDS were purchased from Sigma. VP16 was obtained from Pudong Pharmaceutical Factory (China) and HCPT from Feiyun Pharmaceutical Factory (China). Other chemicals used were all of analytical reagent grade. Human DNA Topo I was gifted by ZHOU Shi-Ning (Sun Yat-Sen University, China) [17].

2.2. Topo II Preparation. Topo II was extracted from L1210 leukemic cells in peritoneal cavity 7 days after tumor inoculation following the procedure of De Isabella et al. $[12,18]$. In brief, harvested L-1210 cells from DBA/2 mouse were resuspended in $10 \mathrm{~mL}$ of buffer $\mathrm{A}$ ( $10 \mathrm{mM}$ Tris ( $\mathrm{pH} 7.5)$, $1.5 \mathrm{mM} \mathrm{MgCl}_{2}$, and $10 \mathrm{mM} \mathrm{NaCl}$ ) and allowed to sit at $0^{\circ} \mathrm{C}$ for $10 \mathrm{~min}$. A nonionic detergent ( $1 \mathrm{~mL}$ of $10 \%$ Nonidet P40) was added, and the mixture gently triturated and finally left at $0^{\circ} \mathrm{C}$ for $15 \mathrm{~min}$. The cells were then homogenized and centrifuged at $2500 \mathrm{rpm}$ for $10 \mathrm{~min}$, and the pellet was resuspended in $2 \mathrm{~mL}$ of buffer $\mathrm{B}(50 \mathrm{mM}$ Tris ( $\mathrm{pH} 7.5)$, $25 \mathrm{mM} \mathrm{KCl}_{2} 2 \mathrm{mM} \mathrm{CaCl}_{2}, 3 \mathrm{mM} \mathrm{MgCl}_{2}$, and $0.25 \mathrm{M}$ sucrose). The nuclei thus obtained were layered over $0.6 \mathrm{~mL}$ of buffer $\mathrm{C}$ (buffer B with $0.6 \mathrm{M}$ sucrose) and sedimented at $7000 \mathrm{rpm}$ for $10 \mathrm{~min}$. The pellet was resuspended in $2 \mathrm{~mL}$ of buffer $\mathrm{D}$ (buffer B without $\mathrm{CaCl}_{2}$, and with $5 \mathrm{mM} \mathrm{MgCl}_{2}$ ), centrifuged at $7000 \mathrm{rpm}$ for $10 \mathrm{~min}$, and finally resuspended in $0.3 \mathrm{~mL}$ of buffer E (same as buffer D without sucrose). The solution was added $30 \mu \mathrm{L}$ of $0.2 \mathrm{M}$ EDTA $(\mathrm{pH} 8.0)$ and $0.66 \mathrm{~mL}$ of buffer $\mathrm{F}$ ( $80 \mathrm{mM}$ Tris ( $\mathrm{pH} 7.5$ ), $2 \mathrm{mM}$ EDTA, $1 \mathrm{mM}$ DTT, $0.53 \mathrm{M} \mathrm{NaCl}$, and $20 \%$ glycerol (v/v)). This mixture was gently triturated, left at $0^{\circ} \mathrm{C}$ for $30 \mathrm{~min}$, and centrifuged at $40000 \mathrm{rpm}$ for $20 \mathrm{~min}$. The supernatant from the last centrifugation contains Topo II activity, which was examined by the DNA relaxation assay. One unit of Topo II was defined as the amount of enzyme required to fully relax $0.5 \mu \mathrm{g}$ of supercoiled DNA under the conditions described below.

2.3. DNA Relaxation Assay. Topoisomerases were assayed by relaxation of supercoiled plasmid DNA $[19,20]$. Relaxation of $250 \mathrm{ng}$ of supercoiled by Topo I (2 U) was performed in $20 \mu \mathrm{L}$ of Topo I relaxation buffer $(10 \mathrm{mM}$ tris- $\mathrm{HCl}, \mathrm{pH}$ 7.9, $1 \mathrm{mM}$ EDTA, $150 \mathrm{mM} \mathrm{NaCl}, 0.1 \%$ (w/v) BSA, $0.1 \mathrm{mM}$ spermidine, $5 \%(\mathrm{v} / \mathrm{v})$ glycerol), in the presence and absence of varying amounts of the test compounds, dissolved in dimethyl sulfoxide ( $5 \%(\mathrm{v} / \mathrm{v})$ final concentration). Reactions were started by the addition of DNA. Control groups were either DNA alone or DNA treated with topoisomerase. Relaxation of supercoiled DNA with Topo II was performed in Topo II relaxation buffer $(50 \mathrm{mM}$ Tris- $\mathrm{HCl}, \mathrm{pH} 8.0$, $0.5 \mathrm{mM}$ ATP, $10 \mathrm{mM} \mathrm{MgCl}, 120 \mathrm{mM} \mathrm{NaCl}$, and $0.5 \mathrm{mM}$ dithiothreitol). DNA was added before the addition of Topo II. After $30 \mathrm{~min}$ at $37^{\circ} \mathrm{C}$, the reaction was terminated by the addition of $1 \%(\mathrm{w} / \mathrm{v})$ SDS and digested with $50 \mathrm{mg} / \mathrm{mL}$ proteinase $\mathrm{K}$ at $55^{\circ} \mathrm{C}$ for $30 \mathrm{~min}$. DNA was extracted with an equal volume of chloroform/isoamyl alcohol (24:1) and separated on $1 \%(\mathrm{w} / \mathrm{v})$ agarose gel in Tris-acetate-EDTA (TAE) buffer (40 mM trisacetate, $\mathrm{pH} 8.0$, and $2 \mathrm{mM}$ EDTA) at $2 \mathrm{~V} / \mathrm{cm}$ for $3.5 \mathrm{~h}$. Gels were stained with $5 \mathrm{mg} / \mathrm{mL}$ ethidium bromide, destained, and photographed using Polaroid 665 film or a gel-imaging system for numerical quantification by densitometry scanning (Herolab, Wiesloch, Germany).

2.4. Comet Assay. Nuclei were isolated from P388 cells by incubating whole cells in nuclear buffer $\left(5 \mathrm{mM} \mathrm{MgCl}_{2}\right.$,

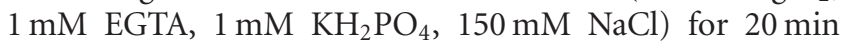
on ice with gentle rocking. Plasma membrane disruption and nuclei integrity was checked under the microscope. Isolated nuclei were exposed to Van-7 or HCPT at $40 \mu \mathrm{M}$ for $30 \mathrm{~min}$ at $37^{\circ} \mathrm{C}$. DNA break was detected as previously described [21]. Briefly, nuclei were embedded in agarose gel and then spread on a polylysinated microscope slide. 
Nuclei were lysed in lysis buffer $(2.5 \mathrm{M} \mathrm{NaCl}, 10 \mathrm{mM}$ Tris$\mathrm{HCl}, 100 \mathrm{mM} \mathrm{Na}_{2}$ EDTA, 1\% Triton, 10\% DMSO, pH 10) for $1 \mathrm{~h}$ at $4^{\circ} \mathrm{C}$. After lysis, nuclei were preincubated for $20 \mathrm{~min}$ at $4^{\circ} \mathrm{C}$ in the electrophoresis buffer $(0.3 \mathrm{M} \mathrm{NaOH}, 1 \mathrm{mM}$ $\mathrm{Na}_{2}$ EDTA, pH 13.5) and then subjected to alkaline gel electrophoresis $\left(300 \mathrm{~mA}, 4^{\circ} \mathrm{C}, 20 \mathrm{~min}\right)$. Slides were analysed by laser scanning microscopes (LSM, Zeiss Ltd.) to quantitative DNA damage. The tail moment, calculated with Komet 5.5 software (Kinetic Imaging, Bath, UK) by multiplying the total intensity of the comet tail by the migration distance from the center of the comet head, was used to measure DNA damage. Fifty nuclei for each experimental point were scored blind from two slides. The frequency distribution was defined as the percentage of number of cells with tail moment value in total cells scored.

2.5. Measurement of Topo-I Mediated DNA Cleavage. Reaction mixtures containing pBR322 DNA (250 ng) and excess of enzymes (i.e., $100 \mathrm{U}$ of Topo-I) and drugs were incubated at $37^{\circ} \mathrm{C}$ for $30 \mathrm{~min}$. Samples, which contained tested drugs, were assembled in this order: DNA, Topo-I, Van-7, or HCPT. The reactions were terminated by the adding $1 \%$ SDS and $150 \mathrm{mg} / \mathrm{mL}$ proteinase $\mathrm{K}$. After the additional $30 \mathrm{~min}$ incubation at $37^{\circ}$, DNA samples were electrophoresed in $1 \%$ agarose gel containing $0.5 \mathrm{mg} / \mathrm{mL}$ ethidium bromide.

2.6. Analysis of Topo I/DNA Binding by EMSA. EMSA (electrophoretic mobility shift assay) was basically performed as described elsewhere [22]. In brief, $250 \mathrm{ng}$ of supercoiled pBR322 DNA was incubated in $20 \mu \mathrm{L}$ of relaxation Topo I buffer with or without excess of Topo I $(100 \mathrm{U})$ in the presence of the test compounds at $37^{\circ} \mathrm{C}$ for $6 \mathrm{~min}$. The reaction was started by the addition of DNA. The samples containing test compounds were assembled in the order of Topo I, HCPT, or Van-7. Samples were immediately loaded onto the $0.8 \%$ agarose gel in Tris-acetate-EDTA buffer with $1 \mu \mathrm{g} / \mathrm{mL}$ ethidium bromide and separated by electrophoresis for $6 \mathrm{~h}$ at $2 \mathrm{~V} / \mathrm{cm}$.

2.7. Ethidium Bromide Displacement Fluorescence Assay. Ethidium bromide displacement fluorescence assay [23] was employed to determine whether Van-7 binds to DNA. Fluorescence emission spectra $\left(\lambda_{\max }=600 \mathrm{~nm}\right.$, excitation wavelength $546 \mathrm{~nm}$ ) were obtained at $25^{\circ} \mathrm{C}$ on a Beckman fluorescence spectrophotometer. The assays contained $1 \mu \mathrm{M}$ ethidium bromide, $0-100 \mu \mathrm{M}$ Van-7, and $1 \mu \mathrm{g}$ supercoiled pBR322 DNA in $2 \mathrm{~mL}$ of fluorescence buffer.

2.8. Measurement of DNase I Activity. Bovine DNase I (4.0 U/ $\mathrm{mL}$ ) was incubated with $400 \mathrm{ng}$ of pBR322 DNA in $20 \mu \mathrm{L}$ of buffer $\left(50 \mathrm{mM}\right.$ Tris- $\mathrm{HCl}, \mathrm{pH} 7.5,10 \mathrm{mM} \mathrm{MnCl}_{2}$, and $50 \mu \mathrm{g} / \mathrm{mL} \mathrm{BSA})$ in the presence of Van-7 $(50-100 \mu \mathrm{M})$ for $15 \mathrm{~min}$ at $37^{\circ} \mathrm{C}$. The reaction was stopped by the addition of $25 \mathrm{mM}$ EDTA (final concentration) and followed by agarose gel electrophoresis.

2.9. MTT Assay. A549, Hela, BEL-7402, P388, and L-02 cells were purchased from American Type Culture Collection
(ATCC). Culture media were selected according to ATCC suggestions. To perform growth experiments cells were seeded (10,000 cells/well) in 96-well flat bottom plates. After $24 \mathrm{~h}$ the media were replaced, and, after one washing, media containing the drugs were added. After $48 \mathrm{~h}$ incubation at $37^{\circ} \mathrm{C}$, MTT solution was added at $5 \mathrm{mg} / \mathrm{mL}$ and incubated for an additional $4 \mathrm{~h}$. Then culture supernate was removed, and $150 \mu \mathrm{L}$ dimethyl sulfoxide (DMSO) was added per well to dissolve the formazan crystals. Colorimetric determination was made at $570 \mathrm{~nm}$ using a microplate reader (Spectra Rainbow, Austria). Six parallel samples were prepared in each group, and each experiment has been replicated for three times. A dose-response study was performed to calculate the $50 \%$ inhibiting concentration $\left(\mathrm{IC}_{50}\right)$ for Van-7. $\mathrm{IC}_{50}$ calculated by the application of the Reed and Muench method [24] is as follows:

$$
\mathrm{IC}_{50}=\operatorname{antilog}\left\{A+\left[\left(\frac{B}{C}\right) D\right]\right\},
$$

where $A$ is $\log$ concentration below $50 \%$ mortality, $B$ is $50-$ mortality below $50 \%, C$ is mortality above $50 \%-$ mortality below $50 \%$, and $D$ is $\log$ concentration above $50 \%-\log$ concentration below $50 \%$.

2.10. Flow Cytometry. A549 human lung cancer cells were seeded (300,000 cells/well) in 6-well flat bottom plates. After an incubation in F-12 medium containing 10\% FCS (v/v) at $37^{\circ} \mathrm{C}$ for $24 \mathrm{~h}$, Van-7 was added at $100 \mu \mathrm{M}, 50 \mu \mathrm{M}, 25 \mu \mathrm{M}$, $12.5 \mu \mathrm{M}$ (final concentration), and HCPT at $40 \mu \mathrm{M}$ except the blank control group. 48 h later, A549 cells were harvested, washed three times with phosphate-buffered saline (PBS), stained with PI for $30 \mathrm{~min}$, gated and analyzed by FCM (Becton and Dickinson, Vantage, USA) with a $488 \mathrm{~nm}$ laser excitation and a $530 \mathrm{~nm}$ emission filter. Data were analyzed with Modfit 2.0 and two parallel samples were prepared in each group, and each experiment was replicated for three times.

2.11. Statistical Analysis. Comparisons of treatment outcomes were tested for statistically significant differences using Student's $t$-test for paired data. Statistical significance was assumed at ${ }^{*} P \leq 0.05,{ }^{* *} P \leq 0.01$, and ${ }^{* * *} P \leq 0.001$.

\section{Results}

3.1. Inhibition of the Activity of Topo I but Not Topo II by Van7. The effects of Van-7 on topoisomerases were investigated using a conventional plasmid DNA relaxation assay. HCPT, a well-known Topo I inhibitor, was employed as a positive control. A representative experiment is shown in Figure 2, the inhibition of the DNA relaxation activity of Topo I by HCPT or Van-7 was in concentration-dependent manner. We found that Van-7 at the concentration of $5 \mu \mathrm{M}$ obviously inhibited the DNA relaxation activity of Topo I, while HCPT did not have such effect as no visible electrophoresis band of supercoiled DNA was displayed at $5 \mu \mathrm{M}$. In additional, Van7 also completely inhibited the DNA relaxation activity of Topo I at the concentration of $40 \mu \mathrm{M}$. These results suggest that Van-7 is a more potent inhibitor of Topo I than HCPT. 
TABLE 1: $\mathrm{IC}_{50}(\mu \mathrm{M})$ values obtained after $72 \mathrm{~h}$ of continuous Van-7 exposure.

\begin{tabular}{cccccc}
\hline Cell lines & P388 & BEL-7402 & A549 & Hela & L-02 \\
\hline & $0.9 \pm 0.2$ & $5.3 \pm 1.1$ & $0.1 \pm 0.04$ & $5.1 \pm 1.2$ & $60.2 \pm 7.6$ \\
\hline
\end{tabular}

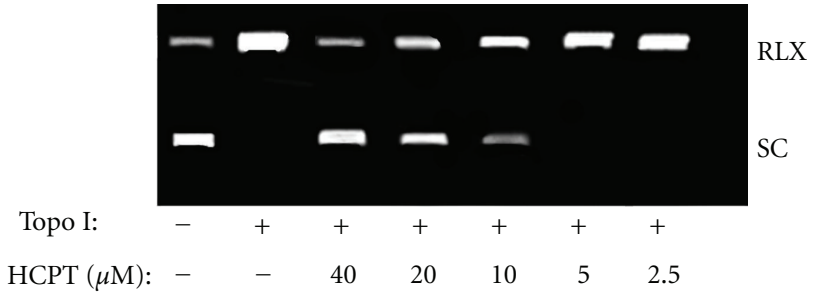

(a)

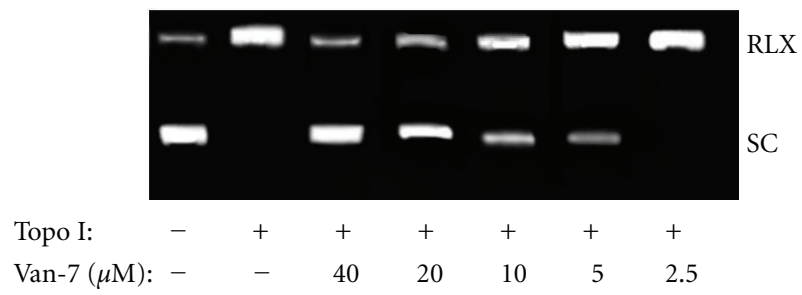

(b)

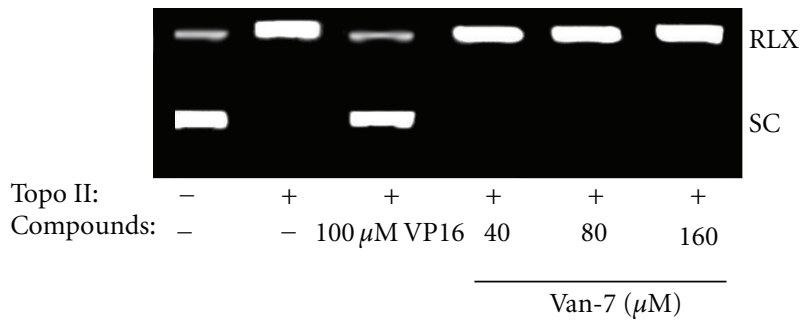

(c)

Figure 2: (a) Effect of HCPT on Topo I-mediated supercoiled pBR322 relaxation. (b) Effect of Van-7 on Topo I-mediated supercoiled pBR322 relaxation. Both of the two reactions were carried out without ATP. (c) Effect of Van-7 on Topo II-mediated supercoiled pBR322 relaxation. The reaction was carried out in presence of ATP. RLX: relaxed DNA, a circular DNA molecule that has no superhelical turns. SC: supercoiled DNA,over- or underwinding of a DNA strand.

To investigate if Van-7 is a selective inhibitor of Topo I, we further tested its effect on the catalytic activity of Topo II. As shown in Figure 2(c), no inhibitory activity was observed against Topo II, even up to the concentration of $160 \mu \mathrm{M}$. On the contrary, VP16, a well-known Topo II inhibitor, obviously inhibited the strand passage activity of Topo II at $100 \mu \mathrm{M}$.

3.2. Van-7 Does Not Induce Cleavable Complex Formation Like HCPT. Topo I acted as a single-strand endonuclease and ligase, and HCPT inhibits ligase without affecting the cleavage step. Therefore, HCPT entraps a slow migrating complex formed by the enzyme, the drug, and DNA, named as cleavable complex [25]. We further assessed whether Van7 also induced the formation of the cleavable complexes. As shown in Figure 3(a), obvious increase of electrophoresis band for open circle was observed after HCPT treatment, suggesting that HCPT could induce formation of cleavable complex; however, Van-7 was not similar to HCPT as no obvious cleavable complex was found comparing with control group, suggesting that inhibitory mechanism of Van7 against Topo I is different from that of HCPT.

To further consolidate the presumption above, the freshly isolated cell nuclei were treated for $30 \mathrm{~min}$ with the compound, and the occurrence of DNA breaks was assessed by comet assay (Figure 3(b)). By comet assays, HCPT was found to be able to induce DNA breaks with obvious formation of comet tail, whereas Van-7 was unable to produce a similar effect.

3.3. Van-7 Exhibits Notable DNA-Binding Activity via the Intercalative Mode. We next investigated whether Van-7 directly interfered with binding of Topo I to DNA using an EMSA assay. Here, HCPT was selected as a control because it can inhibit the ligase activity and does not interfere with the binding of the enzyme to DNA [26]. As shown in Figure 4(a), Van-7 at $100 \mu \mathrm{M}$ significantly hampered the binding of the enzyme to DNA, and this did not occur with HCPT as expected.

Ethidium bromide is a large, flat basic molecule that resembles a DNA base pair. Because of its chemical structure, it can intercalate (or insert) into a DNA strand. Displacement of ethidium bromide from DNA with concomitant reduction in ethidium fluorescence was used as an approach to examine whether a compound could intercalate into DNA. As shown in Figure 4(b), with the increase of Van-7, marked reduction in fluorescence intensity was found accordingly, suggesting that ethidium bromide could be displaced by Van-7 from DNA strand. This result indicates that Van-7 can intercalate into DNA and bind to DNA.

3.4. Van-7 Does Not Affect the Activity of DNase I. We further detected the effect of Van-7 on the catalytic activity of bovine DNase I. As shown in Figure 5, with Van-7 even up to $100 \mu \mathrm{M}$ or without Van-7, the DNase I could digest DNA indistinguishably, suggesting that Van-7 does not affect the catalytic activity of DNase I.

3.5. The Cytotoxicity Activities of Van-7 In Vitro. Van-7 was tested in four human cancer cell lines to observe its anticancer activities in vitro. Data were shown in Table 1; Van-7 was able to significantly inhibit the growth of the cancer cell lines, but show faint inhibition activity to human normal liver cell line L- 02 . 


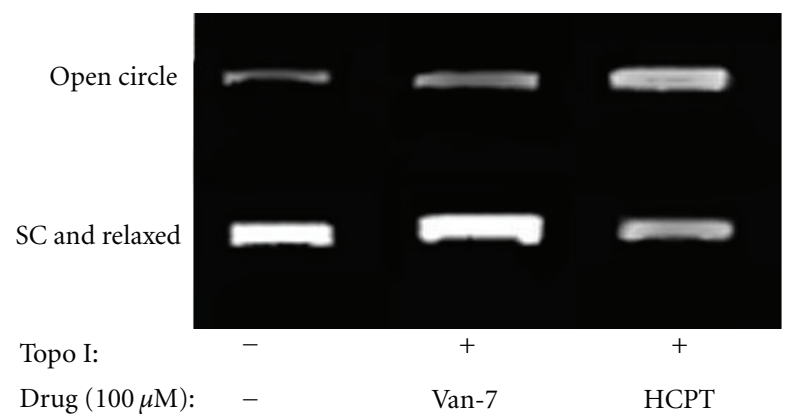

(a)
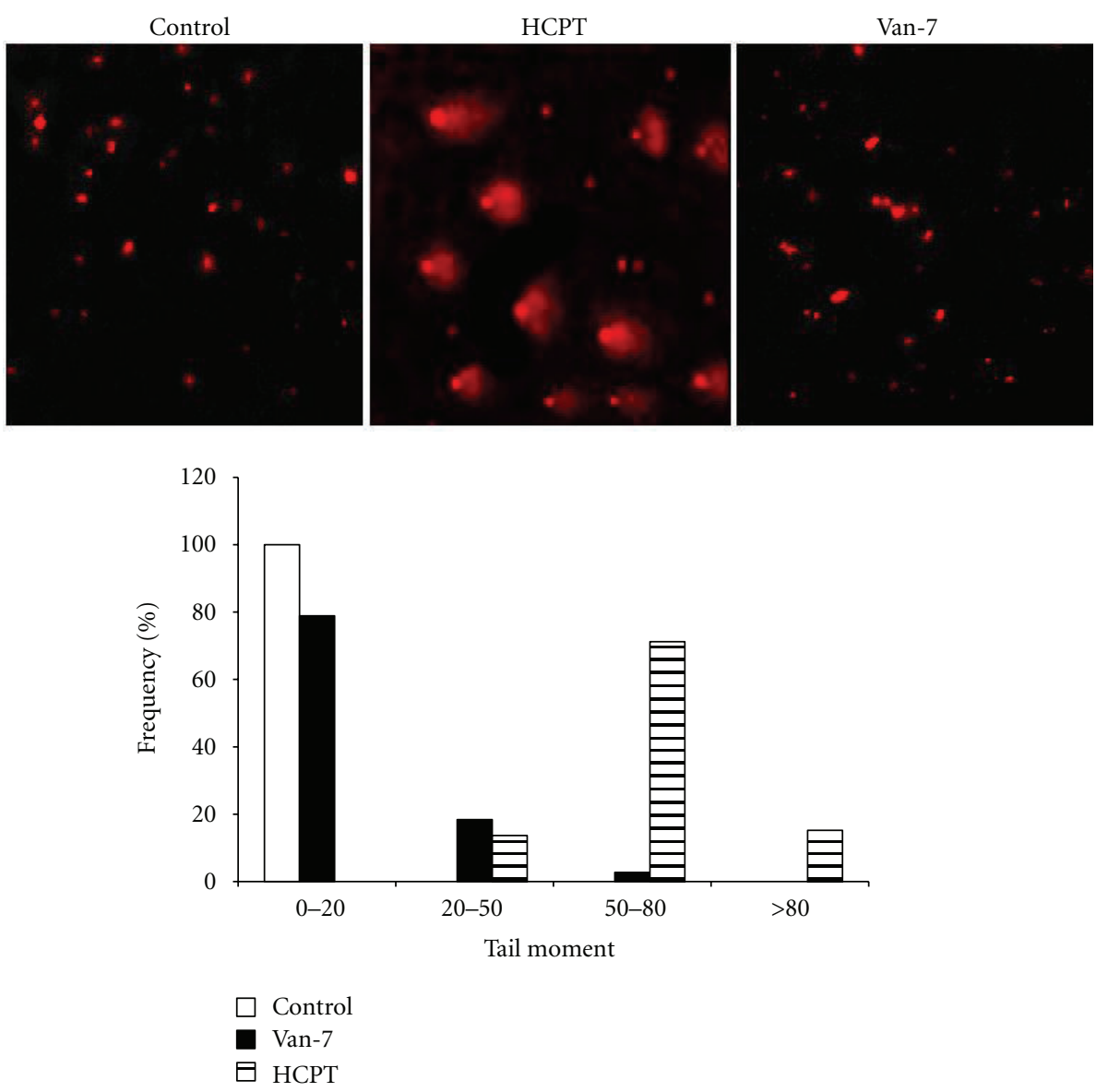

(b)

FIGURE 3: (a) Representative image of agarose gel electrophoresis of the cleavage assay. Only HCPT induced the formation of a slow migrating complex formed by enzyme, drug, and DNA, whereas Van-7 did not. (b) Comet assay performed in isolated nuclei in the presence of the vehicle, HCPT $(40 \mu \mathrm{M})$, or Van-7 $(40 \mu \mathrm{M})$. Tail moment for each comet was calculated. Nuclei were grouped according to the tail moment value in three groups, and the frequency distribution is shown in the bar chart. DNA damage is increased in nuclei with the highest tail moment values.

3.6. Van-7 Arrests A549 Cell Line at G2/M Phase. To clarify the pattern of Van-7-induced growth suppression, A549 cells were treated with HCPT or Van-7 for 48 hours and analyzed by flow cytometry. Flow cytometry analysis showed that Van-7 treatment resulted in the accumulation of cell populations in G2/M phase in a concentration-dependent manner (Figure 6), while HCPT blocked the cells at $S$ phase [27]. Treatment of A549 cells with $100 \mu \mathrm{M}, 50 \mu \mathrm{M}, 25 \mu \mathrm{M}$, and $12.5 \mu \mathrm{M}$ of Van-7 increased the percentage of cells in the $\mathrm{G} 2 / \mathrm{M}$ phase to $49.36 \%, 27.21 \%, 21.10 \%$, and $15.31 \%$, respectively.

\section{Discussion}

Since the discovery of cis-platinum, many transition metal complexes have been synthesized and assayed for antineoplastic activity. In recent years, vanadium-based molecules 


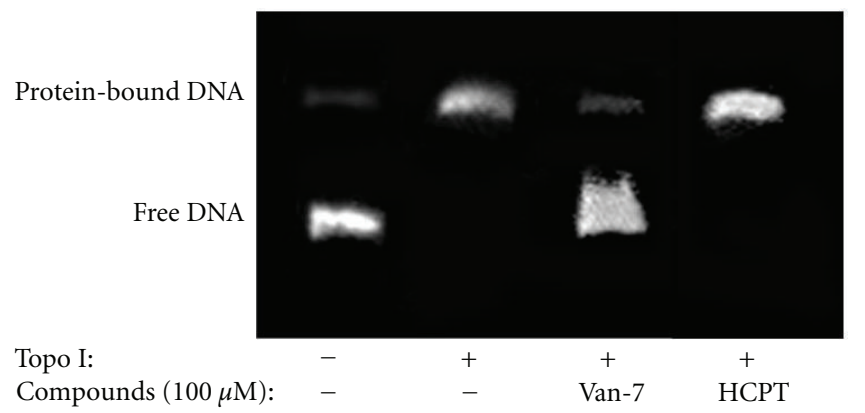

(a)

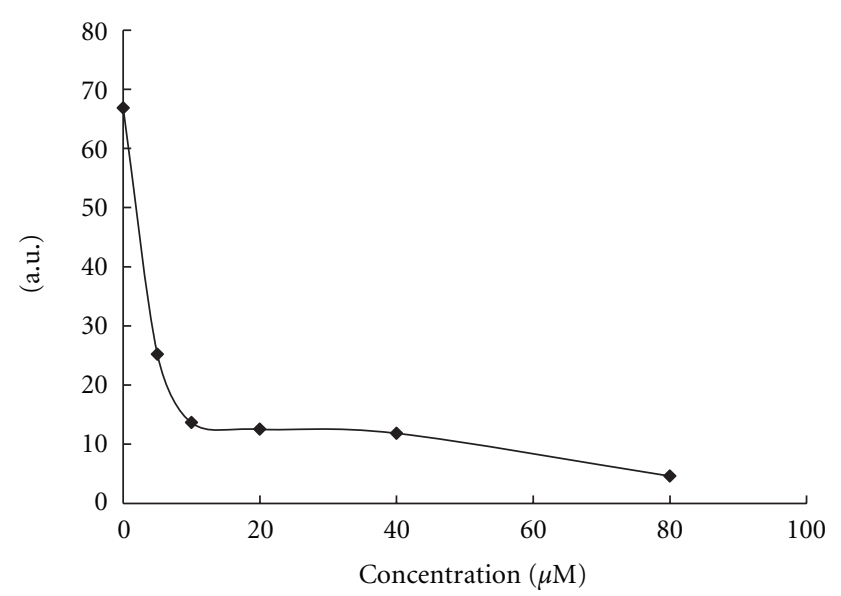

(b)

FIGURE 4: (a) Representative image of the agarose gel electrophoresis for EMSA between pBR322 DNA and Topo I. HCPT did not modulate the formation of the complex DNA/Topo 1, whereas Van-7 significantly hampered the binding of the enzyme to DNA. (b) Van-7 displaces ethidium bromide from DNA strand. The ability of Van-7 to interact with DNA was determined by a fluorescence-based ethidium bromide displacement assay. Samples contained $1 \mu \mathrm{M}$ ethidium bromide and $1 \mu \mathrm{g}$ DNA pBR322. Increasing concentrations of Van-7 were added, and decreasing ethidium fluorescence at $600 \mathrm{~nm}\left(\lambda_{\max }\right)$ was monitored $(546 \mathrm{~nm}$ excitation wavelength).

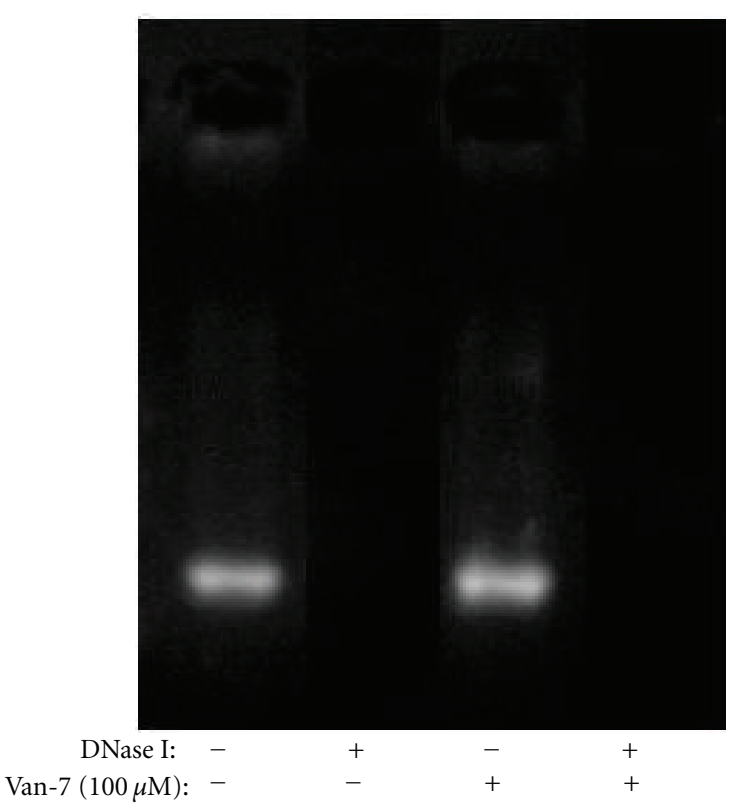

FIGURE 5: Representative image of agarose gel electrophoresis of the DNase assay. Bovine DNase I ( $4.0 \mathrm{U} / \mathrm{mL}$ ) was incubated with $400 \mathrm{ng}$ of pBR322 DNA in the presence of Van-7 $(100 \mu \mathrm{M})$ for $15 \mathrm{~min}$ at $37^{\circ} \mathrm{C}$. Van-7 was unable to interfere with DNase activity. This experiment was repeated three times with similar results.

have emerged as promising anticancer and antimetastatic agents with potential application in platinum-resistant tumors or as alternatives to platinum [14]. In our screening model for inhibitor of DNA topoisomerases, we discover that Van-7, one kind of vanadium compound, has a strongly inhibitory activity to Topo I, not to Topo II.
Topo I inhibitors include Topo I poison and Topo I suppressor. Both of them are agents designed to interfere with the action of topoisomerase enzymes, but the mechanisms are different. HCPT, as a kind of camptothecin derivative, is a typical Topo I poison. HCPT can stabilize DNA Topo I, forming drug DNA Topo I complex and inhibiting Topo I activity [28]. However, suppressor is DNA conjugant (such as Hoechst33258) or intercalator (such as aclacinomycin A). Topo I suppressor combines with DNA or deforms the structure of DNA to inhibit the catalytic activity of Topo I to result in cell death. To exert this effect, most Topo I suppressors must be in relatively high concentration, and the activity of DNA conjugant depends on its closely binding with DNA. In the present paper, Van-7 was found to inhibit the activity of Topo I obviously; however, in the test of drug DNA Topo I complex with gel electrophoresis analysis, Van-7 was not found to form cleavable complex even up to $100 \mu \mathrm{M}$. In order to further evaluate Van-7 a direct involvement in the inhibition of topoisomerase in nucleus independently on some potential interference, freshly isolated cell nuclei were used, and the probable occurrence of DNA breaks was assessed by comet assay. We found that HCPT treatment showed obvious comet tail while Van-7 did not. From the above two results, we confirm that inhibitory effect of Van-7 on Topo I activity is different from that of HCPT, and the fact that Van-7 cannot form Drug-DNA Topo I complex indicates that Van-7 is not a poison. Therefore, we presume that Van-7 acts on the upstream of catalytic reaction and probably disturbs the combination of Topo I with DNA.

DNA mobility shift assay (EMSA), also called gel retardation assay, can be used to detect DNA-protein interaction in vitro. In electric field, DNA fragments binding with protein migrate more slowly to positive pole than free DNA 

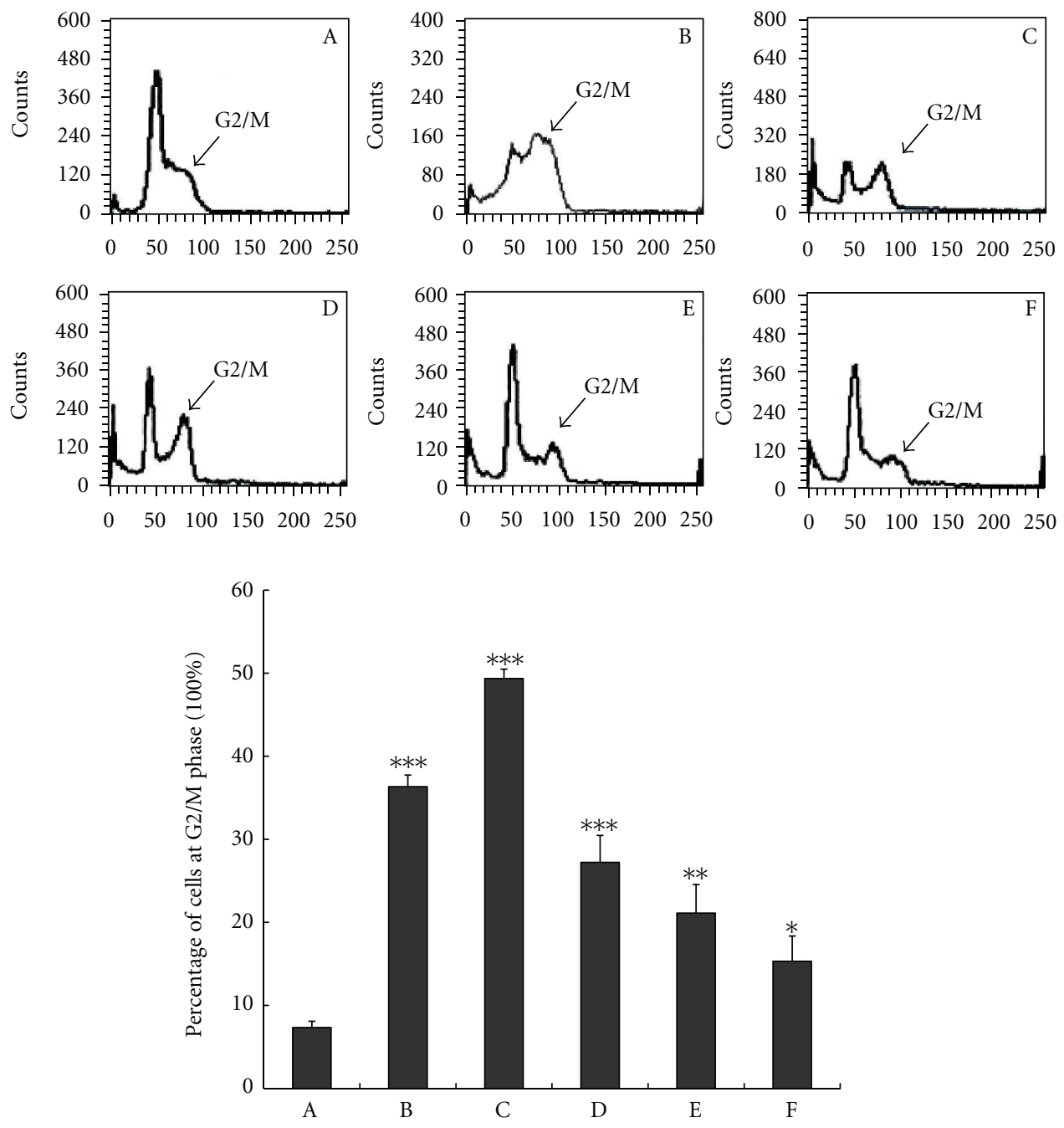

Figure 6: Van-7 arrested A549 cell line at G2/M phase. A: control; B: HCPT, $40 \mu \mathrm{M}$; C: Van-7, $100 \mu \mathrm{M}$; D: Van-7, $50 \mu \mathrm{M}$; E: Van-7, $25 \mu \mathrm{M}$; F: Van-7, $12.5 \mu \mathrm{M}$. The percentage of G2/M, A: 7.32\%; B: 36.32\%; C: 49.36\%; D: $27.21 \%$; E: $21.10 \%$; F: $15.31 \%$. The values were the means \pm $\mathrm{SD}, n=3 .{ }^{*} P<0.05,{ }^{*} P<0.01,{ }^{* * *} P<0.001$ versus control group.

fragments. We further evaluate the effect of the compound on the binding of DNA with Topo I. In our tests, we found that Van-7 at $40 \mu \mathrm{M}$ obviously inhibited the binding of Topo I to DNA with free DNA fragments band in gel electrophoresis. But this phenomenon was not observed in the present of HCPT. In additional, Van-7 significantly reduced the fluorescence intensity by displaceing ethidium bromide from DNA strand. All these results indicate that Van-7 intercalates to DNA and exert its inhibitory effect to Topo I.

DNase I is a nuclease that cleaves DNA preferentially at phosphodiester linkages adjacent to a pyrimidine nucleotide, yielding $5^{\prime}$-phosphate-terminated polynucleotide with a free hydroxyl group on position $3^{\prime}$, which is similar to topoisomerases cutting the phosphate backbone of the DNA; however, Van-7 was not found to affect the activity of Dnase I, which indicates that Van-7 inhibits activity of Topo I with some selectivity.
Topo I has significant consequences for cancer and cancer chemotherapy via their antiproliferative or celldifferentiating action. From the results of MTT tests, Van7 was found to strongly inhibit the growth of tumor cells, such as BEL-740A549 and Hela cells, but not normal cells. As the specific activity of Topo I was about 4-fold greater in proliferating (log phase) cells than in nonproliferating (confluent) cells, and in contrast to the changes in Topo I levels, the specific activity of Topo II showed no detectable difference in proliferating versus non-proliferating cells [29], therefore it is reasonable that Van-7 is more selective to cancer cells with proliferation rate much higher than normal cells. It is reported that the compounds exhibit a different inhibitory mechanism from camptothecin that may induce different phase cell cycle arrest, a novel Topo I inhibitor with repressing the catalytic cleavage activity of Topo I instead of forming the drug-enzyme-DNA covalent ternary complex arrested cell cycle at G2/M phase to K562 Cells [30]. Our 
FACS analysis result that Van-7 in the concentration of $100 \mu \mathrm{M}$ could block the cell cycle to G2-M other than S phase is consistent with this report.

On the whole, we consider that Van-7 is a potential Topo I inhibitor as a kind of Topo I suppressor. Van-7 can insert into DNA base pairs, resulting in DNA structure distortion, and then inhibiting the binding of DNA to Topo 1, finally affecting the catalytic activity of Topo I. To the best of our knowledge, it is the first report about clarifying inhibitory ability of a vanadium metal compounds on Topo-I catalytic activity and its mechanism. However, the anticancer activity in vivo and detail mechanisms of Van-7 requires further investigation.

\section{Abbreviations}

Topo I: Topoisomerase I

Topo II: Topoisomerase II

HCPT: Hydroxycamptothecine

DMSO: Dimethylsulfoxide

VP16: Etoposide.

\section{Authors' Contribution}

X.-m. Mo and Z.-f. Chen contributed equally to this work.

\section{Acknowledgments}

This work was supported by Grants from National High-tech R\&D Program (2011AA09070104) of China and Program for Changjiang Scholars and Innovative Research Team in University (IRT0944).

\section{References}

[1] J. C. Wang, "DNA topoisomerases," Annual Review of Biochemistry, vol. 65, pp. 635-692, 1996.

[2] H. Zhang, J. C. Wang, and L. F. Liu, "Involvement of DNA topoisomerase I in transcription of human ribosomal RNA genes." Proceedings of the National Academy of Sciences of the United States of America, vol. 85, no. 4, pp. 1060-1064, 1988.

[3] L. Yang, M. S. Wold, and J. J. Li, "Roles of DNA topoisomerases in simian virus 40 DNA replication in vitro," Proceedings of the National Academy of Sciences of the United States of America, vol. 84, no. 4, pp. 950-954, 1987.

[4] H. J. Chen and J. Hwang, "Binding of ATP to human DNA topoisomerase I resulting in an alteration of the conformation of the enzyme," European Journal of Biochemistry, vol. 265, no. 1, pp. 367-375, 1999.

[5] S. Salerno, F. Da Settimo, S. Taliani et al., "Recent advances in the development of dual topoisomerase I and II inhibitors as anticancer drugs," Current Medicinal Chemistry, vol. 17, no. 35, pp. 4270-4290, 2010.

[6] J. F. Riou, P. Helissey, L. Grondard, and S. Giorgi-Renault, "Inhibition of eukaryotic DNA topoisomerase I and II activities by indoloquinolinedione derivatives," Molecular Pharmacology, vol. 40, no. 5, pp. 699-706, 1991.

[7] B. Poddevin, J. F. Riou, F. Lavelle, and Y. Pommier, "Dual topoisomerase I and II inhibition by intoplicine (RP-60475), a new antitumor agent in early clinical trials," Molecular Pharmacology, vol. 44, no. 4, pp. 767-774, 1993.

[8] F. Leteurtre, A. Fujimori, A. Tanizawa et al., "Saintopin, a dual inhibitor of DNA topoisomerases I and II, as a probe for drugenzyme interactions," Journal of Biological Chemistry, vol. 269, no. 46, pp. 28702-28707, 1994.

[9] B. Frydman, L. J. Marton, J. S. Sun et al., "Induction of DNA topoisomerase II-mediated DNA cleavage by $\beta$-lapacphone and related naphthoquinones," Cancer Research, vol. 57, no. 4, pp. 620-627, 1997.

[10] M. Galanski, M. A. Jakupec, and B. K. Keppler, "Update of the preclinical situation of anticancer platinum complexes: novel design strategies and innovative analytical approaches," Current Medicinal Chemistry, vol. 12, no. 18, pp. 2075-2094, 2005.

[11] M. Galanski, "Recent developments in the field of anticancer platinum complexes.," Recent Patents on Anti-Cancer Drug Discovery, vol. 1, no. 2, pp. 285-295, 2006.

[12] V. Brabec and J. Kasparkova, "Modifications of DNA by platinum complexes: relation to resistance of tumors to platinum antitumor drugs," Drug Resistance Updates, vol. 8, no. 3, pp. 131-146, 2005.

[13] I. Ott and R. Gust, "Non platinum metal complexes as anticancer drugs," Archiv der Pharmazie, vol. 340, no. 3, pp. 117126, 2007.

[14] A. M. Evangelou, "Vanadium in cancer treatment," Critical Reviews in Oncology/Hematology, vol. 42, no. 3, pp. 249-265, 2002.

[15] A. Bishayee, A. Waghray, M. A. Patel, and M. Chatterjee, "Vanadium in the detection, prevention and treatment of cancer: the in vivo evidence," Cancer Letters, vol. 294, no. 1, pp. 1-12, 2010.

[16] Z. Y. Wu, Y. T. Li, and D. J. Xu, "Diaqua(2,2'-diamino-4,4'bi-1,3-thiazole)oxosulfatovanadium(IV) tetrahydrate," Acta Crystallographica Section C, vol. 61, no. 11, pp. m463-m465, 2005.

[17] G. W. Yang, B. H. Yuan, K. P. Ho, X. Dai, Y. C. Lin, and S. N. Zhou, "Optimization of the expression of human DNA topoisomerase I in Pichia pastoris," Sheng wu Gong Cheng Xue Bao, vol. 20, no. 2, pp. 181-186, 2004.

[18] P. De Isabella, G. Capranico, M. Binaschi, S. Tinelli, and F. Zunino, "Evidence of DNA topoisomerase II-dependent mechanisms of multidrug resistance in P388 leukemia cells," Molecular Pharmacology, vol. 37, no. 1, pp. 11-16, 1990.

[19] D. K. Trask, J. A. DiDonato, and M. T. Muller, "Rapid detection and isolation of covalent DNA/protein complexes: application to topoisomerase I and II.," EMBO Journal, vol. 3, no. 3, pp. 671-676, 1984.

[20] J. R. Spitzner, I. K. Chung, and M. T. Muller, "Eukaryotic topoisomerase II preferentially cleaves alternating purinepyrimidine repeats," Nucleic Acids Research, vol. 18, no. 1, pp. 1-11, 1990.

[21] G. Raspaglio, C. Ferlini, S. Mozzetti et al., "Thiocolchicine dimers: a novel class of topoisomerase-I inhibitors," Biochemical Pharmacology, vol. 69, no. 1, pp. 113-121, 2005.

[22] F. Boege, T. Straub, A. Kehr et al., "Selected novel flavones inhibit the DNA binding or the DNA religation step of eukaryotic topoisomerase I," Journal of Biological Chemistry, vol. 271, no. 4, pp. 2262-2270, 1996.

[23] B. C. Baguley and E. M. Falkenhaug, "The interaction of ethidium with synthetic double-stranded polynucleotides at low ionic strength," Nucleic Acids Research, vol. 5, no. 1, pp. 161-171, 1978. 
[24] L. Gribaldo, S. Casati, L. Figliuzzi, and E. Marafante, "In vitro myelotoxicity of environmental contaminants," Environmental Toxicology and Pharmacology, vol. 6, no. 2, pp. 135-141, 1998.

[25] C. C. Kuo, J. F. Liu, and J. Y. Chang, "DNA repair enzyme, O6-methylguanine DNA methyltransferase, modulates cytotoxicity of camptothecin-derived topoisomerase I inhibitors," Journal of Pharmacology and Experimental Therapeutics, vol. 316, no. 2, pp. 946-954, 2006.

[26] C. García-Estrada, C. F. Prada, C. Fernández-Rubio, F. RojoVázquez, and R. Balaña-Fouce, "DNA topoisomerases in apicomplexan parasites: promising targets for drug discovery," Proceedings of the Royal Society B, vol. 277, no. 1689, pp. 17771787, 2010.

[27] L. Luo, P. Li, H. Peng, Y. Luo, and W. Tang, "Cell cycle block and apoptosis in rabbit lens epithelial cells induced by hydroxycamptothecine," Zhonghua Yan Ke Za Zhi, vol. 38, no. 3, pp. 161-164, 2002.

[28] S. Coderoni, M. Paparelli, and G. L. Gianfranceschi, "Effect of CPT on the calf thymus Topoisomerase I-mediated DNA breakage-reunion reaction: optimal conditions for the formation and reversal of the CPT trapped Topoisomerase I cleavable complex," Molecular Biology Reports, vol. 17, no. 2, pp. 129-134, 1993.

[29] J. V. Tricoli, B. M. Sahai, and P. J. McCormick, "DNA topoisomerase I and II activities during cell proliferation and the cell cycle in cultured mouse embryo fibroblast (C3H 10T1/2) cells," Experimental Cell Research, vol. 158, no. 1, pp. 1-14, 1985.

[30] N. Wu, X. W. Wu, K. Agama et al., "A novel DNA topoisomerase i inhibitor with different mechanism from camptothecin induces G2/M phase cell cycle arrest to K562 cells," Biochemistry, vol. 49, no. 47, pp. 10131-10136, 2010. 


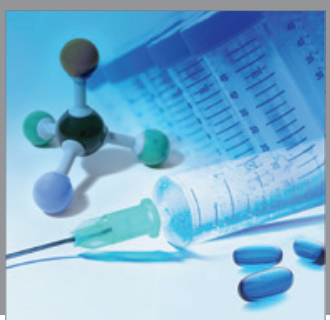

International Journal of

Medicinal Chemistry

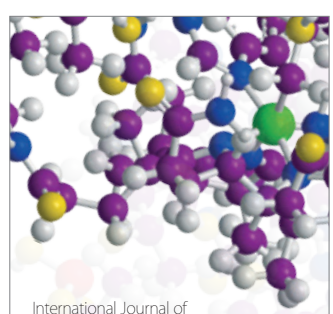

Carbohydrate Chemistry

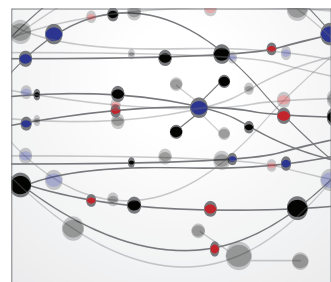

The Scientific World Journal
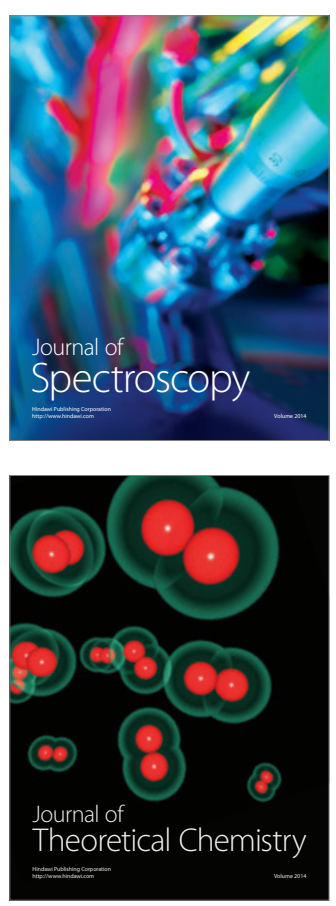
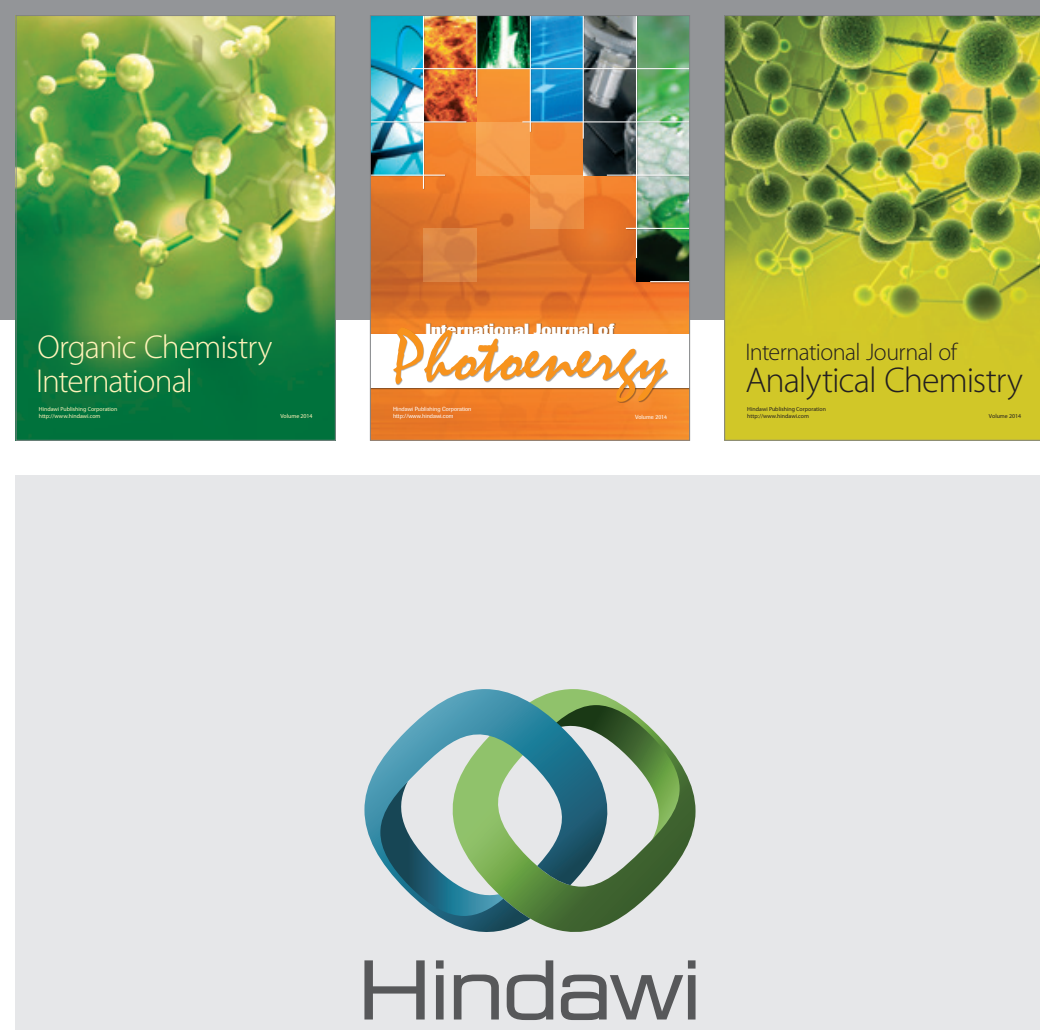

Submit your manuscripts at

http://www.hindawi.com
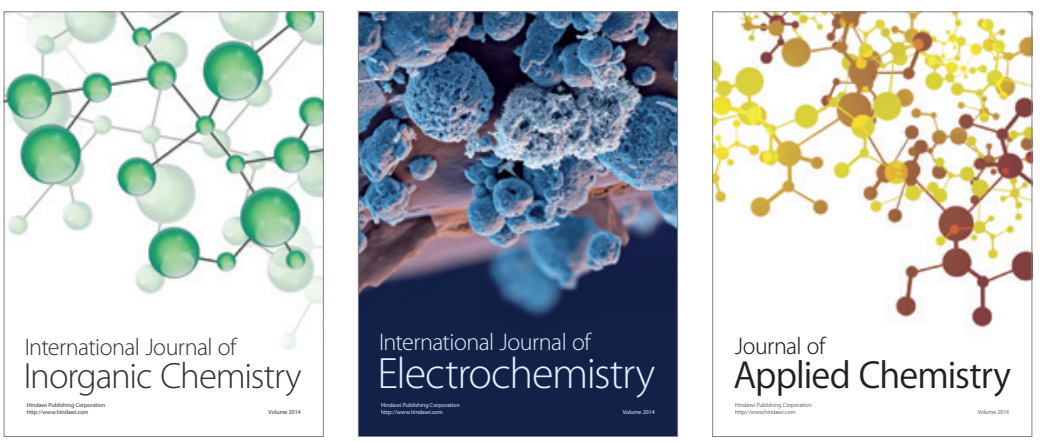

Journal of

Applied Chemistry
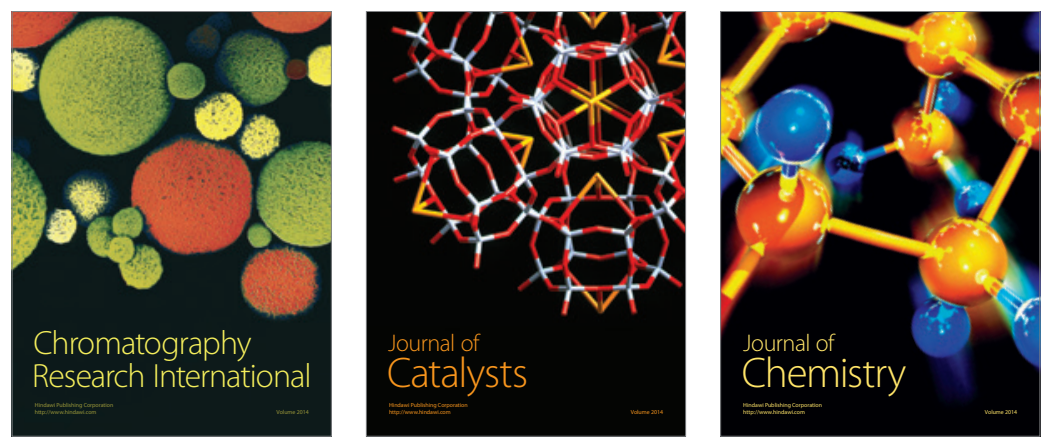
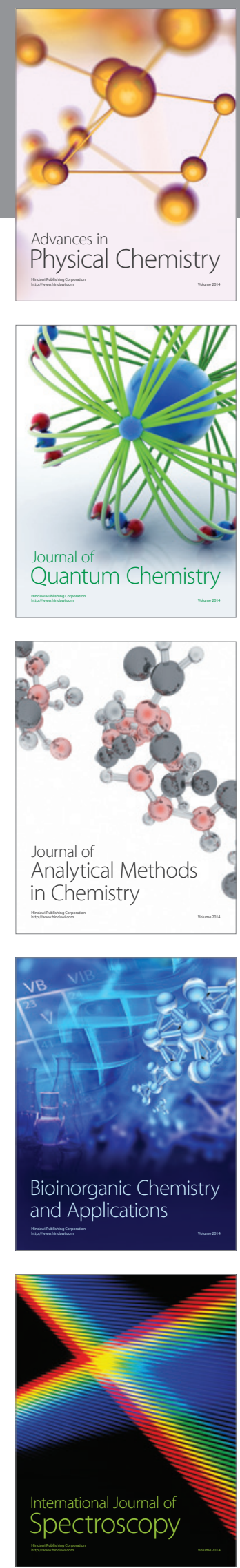